\title{
COMPLEX CHROMOSOME REARRANGEMENTS: REPORT OF THREE PATIENTS
}

\author{
Tsutomu Kamer, ${ }^{1}$ Sei Lee-Okimoto, ${ }^{1}$ Yasushi Yamada, ${ }^{2}$ \\ Kyohko AвE, ${ }^{1,3}$ Tadashi Mastumoto, ${ }^{1}$ \\ and Norio NiIKAWA ${ }^{1}$ \\ ${ }^{1}$ Department of Human Genetics and ${ }^{2}$ Department of Psychiatry, \\ Nagasaki University School of Medicine, Sakamoto-machi 12-4, \\ Nagasaki 852, Japan \\ ${ }^{3}$ Kyushu Medical Science, Cytogenetics Department, \\ Higashi-ku, Matsushima 3-21-7, Fukuoka 813, Japan
}

\begin{abstract}
Summary Three unrelated patients are described, each with a complex, de novo chromosome rearrangement involving four or more break points. One of the patients had few clinical abnormalities and an apparently balanced karyotype with seven break points (1q32, 2q37, 3q26.2, 5q11.2, $5 \mathrm{q} 15,6 \mathrm{q} 25,10 \mathrm{p} 13)$ in six derivative chromosomes. Another patient had multiple congenital anomalies and an apparently balanced complex chromosome rearrangement (CCR) involving four break points $(5 \mathrm{q} 13,5 \mathrm{q} 35$, $8 \mathrm{p} 11,11 \mathrm{p} 15)$ in three derivatives. The other patient showed multiple anomalies and an unbalanced CCR with seven break points (4q21, 4q25, $6 \mathrm{q} 15,6 \mathrm{q} 21,10 \mathrm{p} 13,10 \mathrm{q} 22,10 \mathrm{q} 25)$ in three derivatives including [del(4) (q21q25)]. Each person's parents had normal karyotypes and showed no spontaneous chromosome instability. The fragile sites induced with the FrdU method in two of the three pairs of parents did not correspond to the break points in the CCRs in their offspring. In the last patient, a QFQheteromorphism study revealed that del(4) is of paternal origin. The cause of the CCRs in the three patients is unknown. None of their parents had a history of exposure to teratogenic agents or of radiation of the gonads. None of the parents was an atomic bomb victim although four of them lived in Nagasaki.
\end{abstract}

Received January 8, 1988; revised version received February 25, 1988; Accepted March 12, 1988 This study was supported in part by a Grant-in-Aid for Scientific Research from the Ministry of Education, Science and Culture of Japan (No. 60480468).

Offprint requests to: Tsutomu Kamei, M.D., Department of Human Genetics, Nagasaki University School of Medicine, Sakamoto-machi 12-4, Nagasaki 852, Japan. 


\section{INTRODUCTION}

Congenital complex chromosome rearrangement (CCR) is defined as a congenital chromosome aberration involving three or more break points and with reciprocal exchange of segments between two or more chromosomes (Kousseff et al., 1987). It has been classified into two groups: familial and de novo. Among some 60 CCRs reported, about half are familial and half are de novo (Pai et al., 1980). De novo CCRs involving five or more break points are infrequent, having been reported in only 17 cases (Fukushima et al., 1986; Kousseff et al., 1987).

We report here two cases of de novo CCR involving seven break points and one case with four break points, together with the data on the fragile sites in their parents.

\section{OBSERVATIONS}

Clinical observations. Patient 1 , a girl, was born with a weight of $3,200 \mathrm{~g}$ to healthy parents after a 38 weeks' uneventful pregnancy. When examined by us at the age of 4 years, she had generalized hypotonicity, joint hyperextensibility and severe mental retardation (I.Q. $=25$ ). Bilateral epicanthus was noted. Computerized tomography of the brain revealed mild dilatation of the lateral ventricles.

Patient 2, a female infant, was born at 39 weeks of gestation with a weight of $2,040 \mathrm{~g}$ to healthy parents. She was admitted to our hospital because of neonatal hypoglycemia. On re-examination at the age of 14 months, the following clinical features were noted: developmental retardation (D.Q. $=45$ ), an open sagittal suture of the skull with widely spaced frontal bones, a hairy forehead, low-set and malformed ears, preauricular dimples, wide-set nipples, pigmented external genitalia, an enlarged clitoris, bilateral partial syndactyly of the second and third fingers, pes valgus, fibularly flexed toes, large fifth toes, hypoplastic toe nails, pulmonary stenosis, and generalized hypotonia.

Patient 3 is a male newborn baby whose birth weight and length were appropriate for his gestational age of 41 weeks. He was hospitalized immediately after birth because of neonatal respiratory distress. Abnormal findings included porencephaly, brain atrophy, agenesis of corpus callosum, low-set ears, cleft palate, micrognathia, overlapping fingers, a sacral dimple, deformed feet and developmental retardation.

Cytogenetic observations. Chromosome preparations from the three patients and their parents were obtained from three-day cultures of peripheral blood lymphocytes. Standard GTG-banding revealed complex chromosome rearrangements (CCRs) in all three patients (Figs. 1 and 2$):$ Patient $1: 46, \mathrm{XX}, \mathrm{t}(1 ; 2)(1 \mathrm{pter} \rightarrow 1 \mathrm{q} 32::$ $2 \mathrm{q} 37 \rightarrow 2 \mathrm{qter} ; 2$ pter $\rightarrow 2 \mathrm{q} 37:: 1 \mathrm{q} 32 \rightarrow 1 \mathrm{qter}), \mathrm{t}(6 ; 10)(6 \mathrm{pter} \rightarrow 6 \mathrm{q} 25:: 10 \mathrm{p} 13 \rightarrow 10$ pter $6 \mathrm{qter} \rightarrow 6 \mathrm{q} 25:: 10 \mathrm{p} 13 \rightarrow 10 \mathrm{qter})$, dir ins $(3 ; 5)(3 \mathrm{pter} \rightarrow 3 \mathrm{q} 26.2:: 5 \mathrm{q} 11.2 \rightarrow 5 \mathrm{q} 15:: 3 \mathrm{q} 26.2 \rightarrow$ 


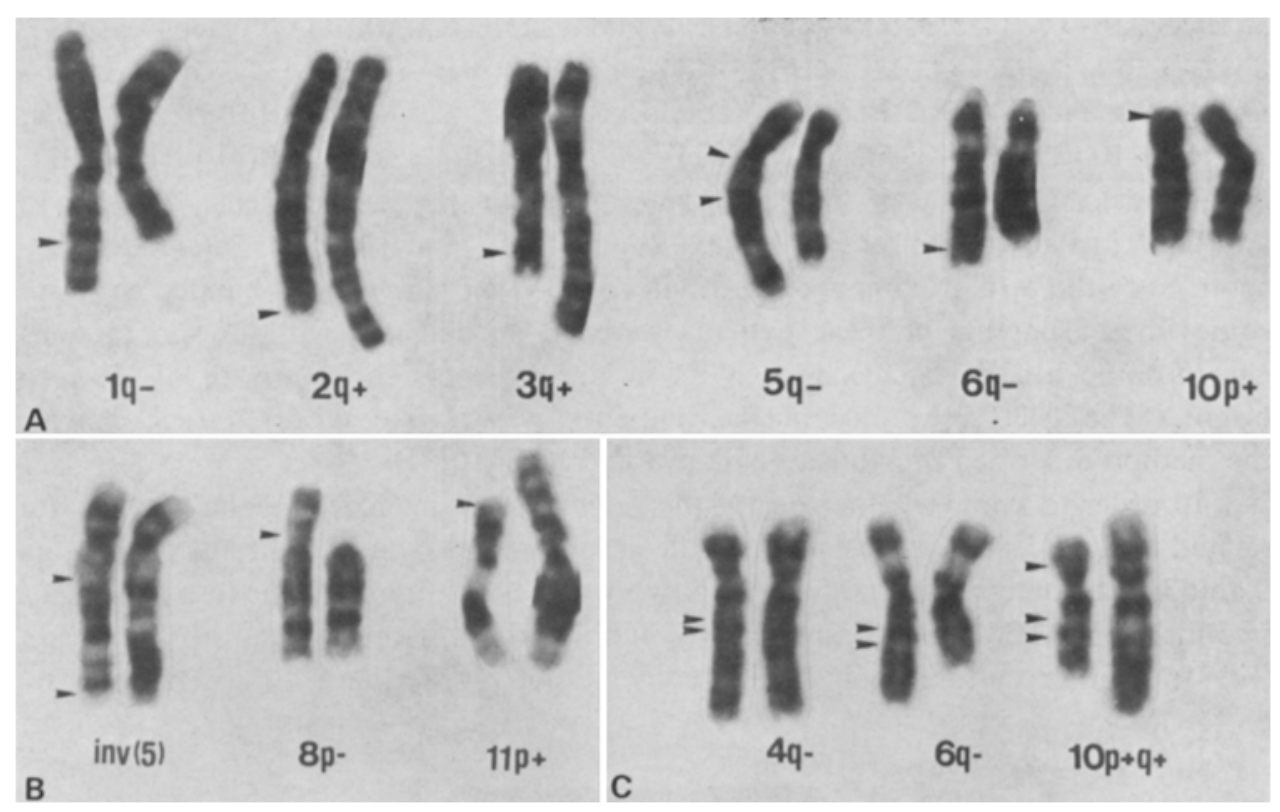

Fig. 1. Partial karyotypes of Patients 1 (A), 2 (B) and 3 (C). Wedges on intact chromosomes (left) show break points for derivative chromosomes (right).

(a)
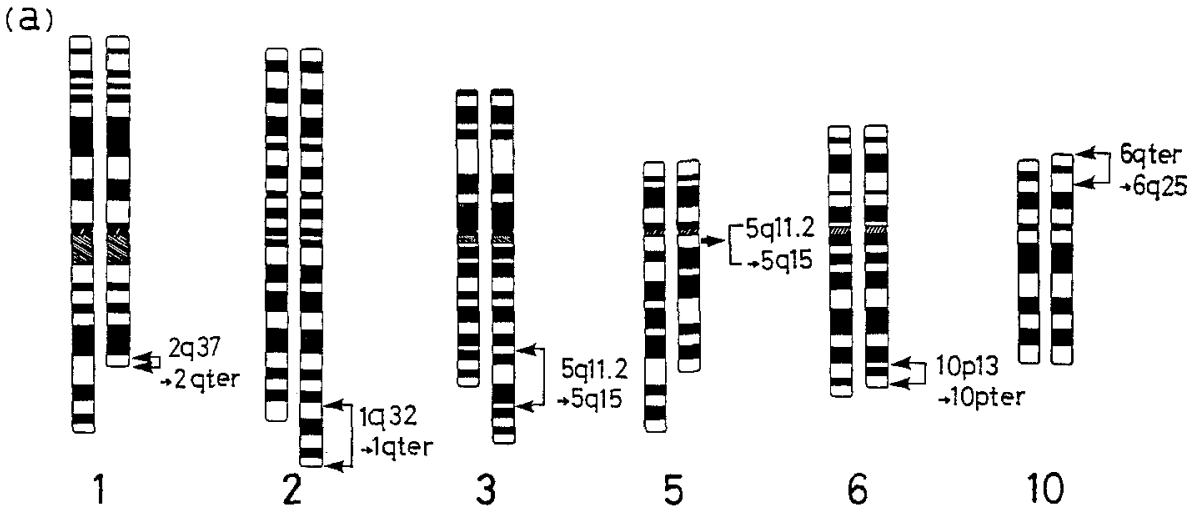

(b)

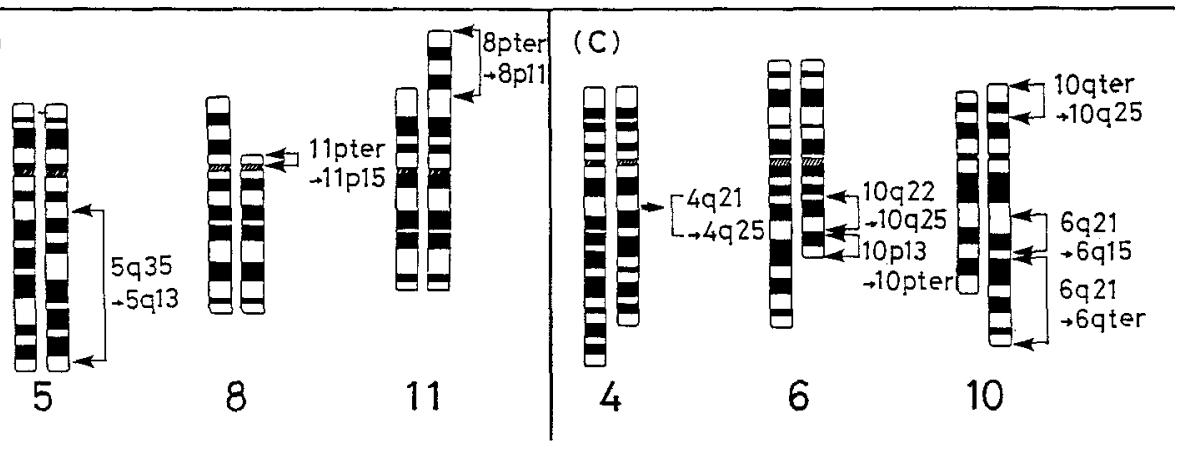

Fig. 2. Diagrams of CCRs in Patients 1 (a), 2 (b) and 3 (c). 
3qter; 5pter $\rightarrow$ 5q11.2:: 5 q 15 $\rightarrow$ 5q ter $)$. Patient $2: 46, X X, t(8 ; 11)(11$ pter $\rightarrow 11$ pl $5::$ $8 \mathrm{p} 11 \rightarrow$ 8qter $; 8$ pter $\rightarrow 8 \mathrm{p} 11:: 11 \mathrm{p} 15 \rightarrow 11 \mathrm{qter}), \operatorname{inv}(5)(\mathrm{pter} \rightarrow \mathrm{q} 13:: \mathrm{q} 35 \rightarrow \mathrm{q} 13:: \mathrm{q} 35 \rightarrow$ qter). Patient $3: 46, X Y, t(6 ; 10 ; 10)(6$ pter $\rightarrow 6 \mathrm{q} 15:: 10 \mathrm{q} 22 \rightarrow 10 \mathrm{q} 25:: 10 \mathrm{p} 13 \rightarrow 10$ pter; $10 \mathrm{qter} \rightarrow 10 \mathrm{q} 25:: 10 \mathrm{p} 13 \rightarrow 10 \mathrm{q} 22:: 6 \mathrm{q} 21 \rightarrow 6 \mathrm{q} 15:: 6 \mathrm{q} 21 \rightarrow 6 \mathrm{qter})$, del(4)(pter $\rightarrow \mathrm{q} 21::$ $\mathrm{q} 25 \rightarrow$ qter). Of a total of 18 break points pooled in the three patients, $2 \mathrm{q} 37,5 \mathrm{q} 15$ and $6 \mathrm{q} 25$ in Patient $1,11 \mathrm{p} 15$ in Patient 2, and $10 \mathrm{q} 22$ and $10 \mathrm{q} 25$ in Patient 3 corresponded to the rare or common fragile sites (HGM8, 1985). GTG-banded chromosomes in the parents of these patients were all normal and without spontaneous chromosome breaks. Thus, the CCRs in the three patients were all of de novo origin. The deleted chromosome 4 in Patient 3 was of paternal origin (Fig. 3) with the method described previously (Niikawa and Kajii, 1984).

In order to know whether or not the de novo rearrangements of the patients are related to fragile sites in their parents, the chromosomes from the parents of Patients 2 and 3 were analyzed in the following two ways: a culture for $72 \mathrm{hr}$ in a folic acidfree medium (MEM-FA, Nissui, Tokyo) supplemented with $5 \%$ fetal bovine serum (FBS); another culture for $72 \mathrm{hr}$ in conventional MEM with $10 \%$ FBS and by

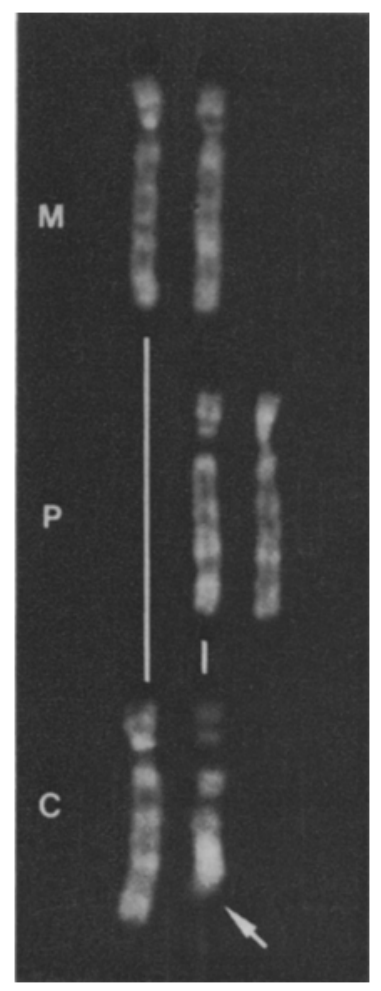

Fig. 3. Q-banded chromosomes 4 of Patient $3(C)$, his mother $(M)$ and his father $(P)$. The del(4) in the patient originated from a chromosome 4 in the father. 
Table 1. Fragile sites observed in the parents of Patients 2 and 3.

\begin{tabular}{|c|c|c|c|c|}
\hline \multirow{3}{*}{ Fragile sites } & \multicolumn{4}{|c|}{ Number of metaphases with fragile site(s) } \\
\hline & \multicolumn{2}{|c|}{ Patient 1} & \multicolumn{2}{|c|}{ Patient 2} \\
\hline & Mother & Father & Mother & Father \\
\hline $1 \mathrm{p} 36$ & 2 & 1 & & 4 \\
\hline $1 \mathrm{p} 22$ & & & & 1 \\
\hline $1 \mathrm{p} 21.2$ & & 1 & & 1 \\
\hline $1 q 21.3$ & 1 & & & \\
\hline $1 \mathrm{q} 25.1$ & & & & 2 \\
\hline $1 \mathrm{q} 42$ & & 1 & & 2 \\
\hline $1 q 44.1$ & & & & 1 \\
\hline $2 \mathrm{q} 13^{\mathrm{a}}$ & & & & 1 \\
\hline $2 q 31$ & & 1 & & 4 \\
\hline $2 q 33$ & & 3 & & \\
\hline $2 q 37.3$ & & & & 1 \\
\hline $3 \mathrm{p} 14.2$ & 3 & 9 & 20 & 13 \\
\hline $3 \mathrm{p} 24.2$ & 1 & 1 & & 1 \\
\hline $3 \mathrm{p} 25^{b}$ & & & 2 & \\
\hline $4 p 16.1$ & & 1 & & 1 \\
\hline $4 q 12$ & 1 & & & \\
\hline $4 q 31.1$ & 3 & & 3 & 1 \\
\hline $5 q 15$ & & & 1 & \\
\hline $5 q 31.1$ & & & 1 & \\
\hline $6 \mathrm{p} 22.2$ & & & 1 & \\
\hline $6 \mathrm{p} 23^{a}$ & & & & 2 \\
\hline $6 \mathrm{q} 25.1$ & 1 & 3 & 2 & 1 \\
\hline $7 \mathrm{p} 13$ & & 1 & & 3 \\
\hline $7 \mathrm{p} 14.2$ & & & 1 & \\
\hline $7 \mathrm{q} 22$ & & 3 & & \\
\hline $7 q 31.2$ & & & & 1 \\
\hline $7 q 32.3$ & 1 & 1 & 4 & 7 \\
\hline $8 \mathrm{q} 22.1$ & & & 2 & 1 \\
\hline $9 q 22.1$ & & & & 1 \\
\hline $9 q 32$ & 2 & & 2 & 1 \\
\hline $11 \mathrm{p} 13$ & & 1 & & \\
\hline $12 \mathrm{q} 24$ & 1 & & & 2 \\
\hline $13 \mathrm{q} 13.2$ & & 1 & & 2 \\
\hline $14 \mathrm{q} 21.2$ & & 1 & & 1 \\
\hline $14 q 23$ & & 1 & & \\
\hline
\end{tabular}

Vol. 33, No. 3, 1988 
Table 1. (Cont'd)

\begin{tabular}{|c|c|c|c|c|}
\hline \multirow{3}{*}{ Fragile sites } & \multicolumn{4}{|c|}{ Number of metaphases with fragile site(s) } \\
\hline & \multicolumn{2}{|c|}{ Patient 1} & \multicolumn{2}{|c|}{ Patient 2} \\
\hline & Mother & Father & Mother & Father \\
\hline $14 \mathrm{q} 24.11$ & & & & 4 \\
\hline $15 q 22$ & & 3 & 2 & \\
\hline $16 \mathrm{q} 22.1$ & & 2 & & \\
\hline $16 \mathrm{q} 23.2$ & 2 & 3 & 6 & 6 \\
\hline $18 \mathrm{q} 21.3$ & & 1 & & \\
\hline $18 \mathrm{q} 23 \mathrm{~b}$ & & & 2 & \\
\hline $20 \mathrm{p} 12.2$ & & & & 1 \\
\hline $\mathrm{Xp} 22.31$ & & 1 & & 4 \\
\hline $\mathrm{Xq} 22.1$ & & 1 & 1 & \\
\hline $\mathrm{Xq} 27.3^{\mathrm{a}}$ & & & 1 & \\
\hline Others $^{c}$ & 9 & 10 & 3 & 9 \\
\hline $\begin{array}{l}\text { Total number } \\
\text { of fragile sites }\end{array}$ & 27 & 51 & 54 & 79 \\
\hline $\begin{array}{l}\text { Number of } \\
\text { cells observed }\end{array}$ & 100 & 100 & 135 & 150 \\
\hline
\end{tabular}

${ }^{a}$ Listed as rare fragile sites in HGM8. Their heredity was not tested in the present families. b Not listed in HGM8, but observed in two or more cells. ${ }^{c}$ Not listed in HGM8, and observed only in one cell.

adding FrdU $\left(10^{-7} \mathrm{M}\right) 24 \mathrm{hr}$ prior to harvest. Metaphase plates from each culture were collected by adding Colcemid $(0.02 \mu \mathrm{g} / \mathrm{ml}) 60 \mathrm{~min}$ prior to harvest. Chromosomes were first stained with Giemsa, photographed, destained, GTG-banded and then re-photographed. In every parent examined, 50 to 100 mitotic cells were analyzed from each culture. None of the revealed fragile sites corresponded to the break points in the rearrangements in the respective patient (Table 1).

\section{DISCUSSION}

The chromosome abnormality in Patient 1 was composed of six derivative chromosomes with seven break points, while that in Patient 2 consisted of three derivatives with at least four break points, and that in Patient 3 involved three derivatives with seven break points. The rearrangements in the three patients were all apparently balanced except for a small interstitial deletion at 4q22-24 in Patient 3. The absence of grave clinical abnormalities in Patient 1 could thus be attributable to her apparently balanced karyotype. The presence of various anomalies in Patient 
2, on the other hand, did not reflect her apparently balanced karyotype. There is a possibility, however, of a submicroscopic deletion or position effect of a gene(s) on her derivative chromosomes. The multiple anomalies observed in Patient 3 are most likely due to the loss of genetic material from chromosome 4 . He shared $\operatorname{del}(4)(\mathrm{q} 21 \mathrm{q} 25)$ and most of his clinical manifestations with a patient reported by Loughman et al. (1979).

The causes that lead to CCRs have not been identified. The importance of extrinsic factors has repeatedly been stressed, such as viral infection and exposure to radiation or chemicals in the parents, particularly the mothers, of the CCR carriers (Kousseff et al., 1987). However, there was no history of such exposure in any of the parents of our patients. Neither the parents nor the patients were exposed to the atomic bomb, although four of the six parents lived in Nagasaki after the Second World War.

Unbalanced CCRs are often de novo in origin. Of 10 such instances, seven, including Patient 3 in this series, had a deletion, while the remaining three had excess chromosome material (Prieto et al., 1978; Pai et al., 1980; McGavran et al., 1982). None of them was a mosaic.

Kleczkowska et al. (1982), in reviewing CCRs in the literature, identified 20 break points preferentially involved in CCR, out of a total of 100 break points observed. Of the 18 break points observed in our three patients, $10 \mathrm{q} 22$ was one of the 20 preferential break points, while another two were among the additional 80 break points. Hecht and Hecht $(1984 \mathrm{a} ; 1984 \mathrm{~b})$ proposed a hypothesis that certain fragile sites may be more susceptible to chromosome breakages in meiosis leading to a chromosome rearrangement in the offspring. None of the fragile sites observed in two pairs of parents in the present study, however, corresponded to the break points in the CCRs in their offspring.

\section{REFERENCES}

Fukushima, Y., Kuroki, Y,, and Ito, T. 1986. Balanced double complex translocations [46,XX, $\mathrm{t}(1 \mathrm{p} ; 6 \mathrm{p} ; 7 \mathrm{p} ; 3 \mathrm{q} ; 11 \mathrm{p})(11 \mathrm{q} ; 22 \mathrm{p} ; 21 \mathrm{q})]$ in an infant with multiple congenital anomalies. Am. J. Med. Genet. 25: 313-317.

Hecht, F. and Hecht, B.K. 1984a. Fragile sites and chromosome breakpoints in constitutional rearrangements. I. Amniocentesis. Clin. Genet. 26: 169-173.

Hecht, F. and Hecht, B.K. 1984b. Fragile sites and chromosome breakpoints in constitutional rearrangements. II. Spontaneous abortions, stillbirth and newborns. Clin. Genet. 26: 174-177.

Human Gene Mapping 8: Helsinki Conference, Eighth International Workshop on Human Gene Mapping. Cytogenet. Cell Genet. 40/1-4.

Kleczkowska, A., Fryns, J.P., and Van den Berghe, H. 1982. Complex chromosomal rearrangements (CCR) and their genetic consequences. J. Génét. Hum. 30: 199-214.

Kousseff, B.G., Nichols, P., Essig, Y-P., Miller, K., Weiss, A., and Tedesco, T.A. 1987. Complex chromosome rearrangements and congenital anomalies. Am. J. Med. Genet. 26: 771-782.

Loughman, W.D., Mitchell, J.A., Packman, S., Grizzard, S., and McWhinney, A. 1979. Interstitial deletion of $4 \mathrm{q}[46, \mathrm{XX}, \operatorname{del}(4)(\mathrm{q} 21.3, \mathrm{q} 26$ ?)] in an infant with congenital anomalies. Am. J. Hum. Genet. 31: 77A. 
McGavran, L., Hagerman, R., McCalmon, R., and Waldstein, G. 1982. A complex karyotype in a child with mild learning disabilities. Am. J. Hum. Genet. 34: 135A.

Niikawa, N. and Kajii, T. 1984. The origin of mosaic Down syndrome: Four cases with chromosome markers. Am. J. Hum. Genet, 36: 123-130.

Pai, G.S., Thomas, G.H., Mahoney, W., and Migion, B.R. 1980. Complex chromosome rearrangements. Clin. Genet. 18: 436-444.

Prieto, F., Badia, L., Moreno, J.A., Barbero, P., and Asenki, F. 1978. 10p-syndrome associated with multiple chromosomal abnormalities. Hum. Genet. 25: 229-235. 